\title{
La producción plástica de María Luisa Fernández: una escultora leonesa en el País Vasco (1986-1993).
}

\author{
Sculptoric Production of María Luisa Fernández: \\ An Artist from Leon in the Basque Country \\ (1986-1993).
}

Iñigo SARRIUGARTE GÓMEZ

Universidad del País Vasco

Resumen: La artista leonesa María Luisa Fernández (Villarejo de Orbigo, 1955) estudia Bellas Artes en la Universidad del País Vasco, donde entra en contacto con una serie de creadores que abogaron de una manera mayoritaria por materiales de carácter industrial y formas muy frías en su nivel expresivo, mientras que María Luisa Fernández mantuvo un interés por el trabajo de la madera, como elemento que recogía sus vivencias más hereditarias, a la vez que intentó romper con la ortodoxia de los parámetros minimalistas, mediante el uso del color, la combinación de materiales y posturas incisivas en las formas, que le acercaron a las pautas de la escultura posminimalista. Igualmente, destaca su postura crítica ante los postulados de los así considerados “artistas ideales" y el uso de los discursos más sexistas en su instalación Burlas Expresionistas del año 1993, fecha donde finaliza el estudio de este texto desde la disolución del colectivo de CVA a mediados de los años 80.

Palabras clave: María Luisa Fernández, Escultura, País Vasco, Posminimalismo, Artistas Ideales, Burlas Expresionistas.

Abstract: The artist Maria Luisa Fernandez from Leon (Villarejo de Orbigo, born in 1955) studied Fine Arts at the University of the Basque Country, where she was in contact with a number of artists, who used in a majority industrial materials and very cold forms in expressive level, while Maria Luisa Fernandez kept an interest in woodworking, as an element that showed her hereditary culture. She tried to break with the orthodoxy of minimalist parameters, through the use of colour, combination of materials and forms with incisive positions, which approached the patterns of postMinimalist sculpture. Also it is representative her critical reflexion about the artists considered ideal and the use of sexist discourses in her installation Burlas Expresionitas from 1993, where finished the study of this text from the dissolution of the collective CVA from the mid of eighties.

Key words: María Luisa Fernández, Sculpture, Basque Country, Posminimalism, Artistas Ideales, Burlas Expresionistas. 


\section{APUNTES BIOGRÁFICOS}

María Luisa Fernández Olivera nace en Villarejo de Orbigo (León), en 1955. Realiza estudios de Bellas Artes (especialidad: Pintura) en la Facultad de Bellas Artes de la Universidad del País Vasco, en 1979-1984.

El primer grupo de compañeros de María Luisa Fernández en la Universidad estuvo formado por Elena Mendizábal, Darío Urzay, Txomin Badiola, José Chavete y Juan Luis Moraza, entre otros. A partir de este encuentro, empieza una relación de amistad, que se mantiene durante los siguientes años de carrera y con posterioridad cuando termina sus estudios universitarios.

María Luisa Fernández, Juan Luis Moraza y Txomin Badiola pertenecen a una generación concreta de la Facultad de Bellas Artes, ubicada desde finales de los 70 hasta principios de los 80 , años marcados por la influencia del arte minimal, el post-minimal y el conceptual. También, durante estos años conoce a Ángel Bados y Peio Irazu, entre otros artistas.

Durante los últimos años de carrera y los posteriores, comparte taller en Uribitarte con Juan Luis Moraza (por aquella época su compañero sentimental). En el taller de la planta de abajo del mismo edificio, estaban Txomin Badiola y Peio Irazu y en otras pisos se encontraban Ángel Bados, Elena Mendizábal y Darío Urzay. En este entorno, al igual que en la facultad, será donde principalmente se debatan numerosos temas de carácter artístico, como el papel del artista, la obra de Oteiza y la postmodernidad.

María Luisa Fernández ha expuesto en varias ocasiones con algunos de sus compañeros de debate, por ejemplo, firmando sus obras como CVA (junto con Juan Luis Moraza) en Bilbao ${ }^{1}$, en el Aula de Cultura de la CAM de Bilbao, en 1984, donde también

\footnotetext{
${ }^{1}$ Este colectivo, cuyas verdaderas siglas siempre se mantuvieron en secreto, a pesar de declarar una larga lista de acepciones, nace en 1979 y se disuelve después de las exposiciones de Mitos y Delitos de 1985 y Nervión en 1986.
}

presentan obra Txomin Badiola, Peio Irazu y Elena Mendizábal, entre otros; Mitos y Delitos, realizada en la Galería Metronom de Barcelona y el Aula de Cultura de la CAM de Bilbao, en 1985, donde también se encontraban piezas de Txomin Badiola, Ángel Bados y José Ramón Sainz Morquillas; Nervión, en la Aula de Cultura de la CAM de Bilbao, en 1986, junto con Txomin Badiola, Peio Irazu, así como José Chavete, Darío Urzay, Elena Mendizábal, etc. De acuerdo con Javier González de Durana, CVA "se desarrolló de manera muy activa entre 1979 y 1985 como empresa artística, manera en la que les gustaba autodenominarse y con la que se alejaban del papel del artista como carismático terminal”2 ${ }^{2}$.

A partir de este año, se produce la disolución definitiva de $\mathrm{CVA}^{3}$, abordando las siguientes exposiciones de manera individualizada, entre las que destacamos Esculturas, Sala Amadís, Madrid, 1987; Desde la escultura en la Galería Ángel Romero de Madrid, en 1986; Siete escultores, Galería Javier Gastavor, Palma de Mallorca, 1989; Burlas Expresionistas, Galería Trayecto, Vitoria-Gasteiz, 1993; Galería Berini, Barcelona, 1995; Artistas Ideales, Sala Carlos III, Universidad Pública de Navarra, Pamplona, 1997, entre otras. Dentro de sus colectivas, destacaríamos Escultura Española Actual, Palacio de Sástago, Zaragoza, 1988; ARCO'89; KUNST

${ }^{2}$ J. GONZÁLEZ DE DURANA, "Esfera dorada", en AA.VV., CVA (1980-1985). Catálogo de la exposición, Vitoria, 2004, p. 5.

${ }^{3}$ Destacan igualmente las siguiente exposiciones individuales de este colectivo: Punto de vista, Sala de Cultura, CAN, Pamplona, 1982; Cicatriú a la matriú, Galería Metrónom, Barcelona, 1983; Casa de Cultura, Basauri y Herrikasarte, Mungia, 1986. Entre otras colectivas, también anotamos Fantastic Art. Ipotesi per un linguaggio Artistico Universal, Centro Documentazione Arti Visive, Castel San Giorgio, Italia, 1980; Espacio Poético Experimental, Casa de España, París, 1980; Tramesa Postal, Metrónom, Barcelona, 1981; La caja en el arte, Galería Windsor, Bilbao, 1982; Fuera de formato (sección documental), Madrid, 1983; Geométricos vascos, Itinerante, 1983; Bilbao 2500, CAM, Bilbao, 1983; Escultura vizcaína actual, Galería Windsor, Bilbao, 1984; Encuentros culturales en Chamartín, Madrid, 1984; El suelo como soporte, Metrónom, Barcelona, 1986. 
RAI-89; Euroarte, Encontro Europeo, Portugal, 1989; Sculptures, CREDAC, Ivry, París, 1990; Dilaciones, exenciones y preceptos, Galería Trayecto, Vitoria-Gasteiz, 1994; Ricas y famosas, Itinerante; Galería Cruce, Madrid, 1997, entre otras tantas.

Posteriormente, imparte clases en distintos institutos de Bilbao, Basauri y Barakaldo. No llega a dar clases en la Universidad del País Vasco, a diferencia de gran parte de sus compañeros, pero sí en la Facultad de Bellas Artes de Pontevedra, donde empieza con la asignatura Arte Ambiental, durante el año 1994. En la actualidad, continúa impartiendo clases en esta universidad, donde se han instalado numerosos profesores que habían sido estudiantes en la Facultad de BB.AA. de la U.P.V., como Javier Tudela, J.C. Román, Juan Loeck, Monika Ortuzar y el mismo Juan Luis Moraza.

Asimismo, ha recibido diferentes becas y premios, destacando los siguientes: 1983-Accésit de Gure Artea y Ayuda de Investigación del Gobierno Vasco; 1985-Accésit del Villa de Bilbao y Primer Premio de Escultura en Gure Artea; 1986-Beca de Escultura del Gobierno Vasco; 1989-Beca Banesto. Igualmente, algunas de sus obras se pueden encontrar en diversas colecciones y museos, como el Museo de Arte Contemporáneo de Barcelona, Museo de Bellas Artes de Álava, Museo Nacional Centro de Arte Reina Sofía y la Colección de Arte Contemporáneo Ciudad de Pamplona, ubicada en la misma ciudad.

\section{REFERENCIAS A LA ESCULTURA POST-MINIMALISTA}

A pesar de que un importante número de los trabajos de M.L.Fernández mantienen una forma cercana a las propuestas del minimalismo, se distancia de la ortodoxia minimalista mediante el uso del color, la combinación de los materiales y la aplicación de características formales y visuales, que rompen la esencia de lo que es un objeto mínimo. En este sentido, sus propuestas se alejarían con rotundidad de la consiguiente descripción que hace Georges Didi-Huberman de este movimiento anterior: "Una aridez sin atractivos, sin contenido. Volúmenes -por ejemplo paralelepípedos- y nada más. Volúmenes que decididamente no indicaban más que a sí mismos. Renunciaban decididamente a toda ficción de un tiempo que los modificaría, los abriría o los llenaría, o cualquier otra cosa" ${ }^{4}$.

Según Robert Pincus-Witten ${ }^{5}$, y tal como lo anuncia Debora Emont-Smith, desde los años 70 irradian diferentes nexos del minimalismo, algunos unidos a estrictas geometrías intrínsecas del Minimal, mientras que otras vertientes tratan de desarrollar tratamientos mucho más abiertos a las cuestiones de las emociones y los sentimientos. Robert Pincus-Witten diferenció la obra realizada después de 1969 de la obra anterior a esa fecha. A tal fin, empleó el término de posminimalismo para distinguir la manipulación más pictórica del material (piezas de plomo fundidas de Richard Serra, colgaduras de látex de Eva Hesse) y la severidad del primer Robert Morris o Donald Judd ${ }^{6}$.

\footnotetext{
${ }^{4}$ G. DIDI-HUBERMAN, Lo que vemos, lo que nos mira, Buenos Aires, 1997, p. 28. Este ensayista francés plantea que en el proceso de desarrollo o interpretación de una imagen de este momento, caracterizada obviamente por las categorías de este momento se debe evitar o trasladar nuestros propios conceptos o gustos sobre las cuestiones del pasado. Por lo tanto, una obra se debería interpretar bajo el mismo tiempo, tal y como lo defiende el mismo autor en Ante el tiempo. Historia del arte y anacronismo de las imágenes, Córdoba, 2011. De hecho, "El historiador sólo es, en todos los sentidos del término, el fictor, es decir, el modelador, el artesano, el autor e inventor del pasado que da a leer. Y, cuando es en el elemento del arte donde va desarrollando su búsqueda del tiempo perdido, el historiador ya ni siquiera se encuentra ante un objeto circunscrito, sino frente a algo parecido a una exposición líquida o aérea -una nueva sin contornos que le pasa por encima cambiando constantemente de forma-. Pero ¿qué podemos conocer de una nube, si no es adivinándola y sin nunca terminar de captarla del todo?", cita extraída de IDEM, Ante la imagen. Pregunta formulada a los fines de una historia del arte, Murcia, 2010, p. 13.

${ }^{5}$ R. PINCUS-WITTEN, Postminimalism into Maximalism. American Art, 1966-1986, Ann Arbor, 1987, p. 3.

${ }^{6}$ R. KRAUSS, Pasajes de la escultura moderna, Madrid, 2002, p. 270.
} 
Lynn Zelevansky afirma que si el minimalismo de la primera mitad de los años sesenta fue, sobre todo, un coto masculino, el posminimalismo surgido a finales de la misma década, aproximadamente al mismo tiempo que el movimiento femenino, fue definido por parte de las mujeres ${ }^{7}$. Las raíces de las obras que aparecen en la exposición Sentido y sensibilidad. Las artistas y el minimalismo en los $90^{8}$ se hallan fundamentalmente en las numerosas expresiones del post-minimalismo, de la escultura anti-form y el process art, el conceptualismo, la performance y el body art. Con el posminimalismo, se evoca lo primario y la factura manual, buscando supuestos equivalentes a algunas metas y estrategias del movimiento femenino. En este sentido, el posminimalismo se ha distanciado adrede de la esfera minimalista, recalcando la sensualidad y el proceso. De hecho, permitió a las mujeres como grupo impactar en el mundo del arte por primera vez, ocurriendo en términos tanto de diálogo crítico como de mercado.

Bajo estas pautas posminimalistas, María Luisa Fernández emplea el óleo con el propósito de fomentar el carácter poético y sentimental. Recordemos que la artista siempre ha abogado por lo emocional $\mathrm{y}$, en este sentido, la utilización del color favorece el carácter poético y expresivo de la obra, de hecho, de no emplearse la coloración, las obras mantendrían un aire de mayor frialdad, mostrando directamente la desnudez del material. Por este motivo, se utilizan diferentes colores en la misma pieza, caso de Lo semejante. Un dios lo junta siempre y Lo semejante. Un dios lo separa siempre, ambas de

${ }^{7}$ L. ZELEVANSKY, "Sentido y sensibilidad. Las artistas y el minimalismo en los noventa", en A.M. GUASCH (ed.), Los manifiestos del arte posmoderno, Madrid, 2000, p. 308 .

${ }^{8}$ Esta exposición se realiza en 1994, en el Museo de Arte Moderno de Nueva York. Encontramos esculturas e instalaciones de siete mujeres artistas (Polly Apfelbaum, Mona Hatoum, Rachel Lachowicz, Jac Leiner, Claudia Matzko, Rachel Whiteread y Andrea Zittel), que emplean elementos asociados al minimalismo, como la repetición, las cuadrículas y las formas geométricas.
1987. Al emplear diferentes cromatismos en la misma escultura se agudizan los componentes diferenciadores y estructurales de la obra. En este sentido, Aurora García afirma respecto a la obra de María Luisa que la utilización del color tiene gran importancia aquí, por lo que él mismo representa, simboliza, y por su integración en la materia, ya que se trata de establecer una competencia entre lo que da la materia y lo que da el color, de manera que ambas posean una significación paralela. Se está recreando una relación y competencia entre estos dos elementos, uno el material, avalado por su dispositivo múltiple de referencias físicas $\mathrm{y}$, por otra parte, la pintura, por su dispositivo aplicativo, en el curso homogeneizador o diferenciador que puede producir en la materia. Confrontados los dos elementos, se plantea buscar un marco de entendimiento y diálogo. En estas obras, se favorece claramente un tratamiento estructural mediante la utilización de distintos colores en diferentes secciones de la pieza. También, este recurso aparece en algunos de los Burladeros, que aparecen en la exposición Burlas Expresionistas, en la Galería Trayecto de Vitoria, en 1993.

Igualmente, aparecen piezas monocromas, generando una mayor conjunción global, caso de Sin título (143 x 127 x 147), Sin título $(107 \times 79 \times 40)$, ambas de $1986^{10} \mathrm{y}$ Lo semejante. No necesita de su igual, de 1987. Esta misma presentación vertical y cilíndrica aparece en numerosas piezas de madera en la instalación de la Galería Berini de Barcelona, en 1991.

En el postminimalismo se empiezan a resaltar las propiedades visuales de la obra. En general, se produce una revalorización expresiva de la pintura y de numerosos materiales, siendo una reacción a la inexpresi-

${ }^{9}$ A. GARCÍA, María Luisa Fernández. Catálogo de la exposición, Madrid: Galería Oliva Mara, 1988, s/n.

${ }^{10}$ A las siguientes obras denominadas Sin título, les añadiremos sus correspondientes medidas, con el propósito de diferenciarlas: Sin título $(250 \times 30 \times 27 \mathrm{~cm})$; Sin título $(79 \times 85 \times 17 \mathrm{~cm})$; Sin título $(143 \times 127 \times 147 \mathrm{~cm})$; Sin título $(107 \times 79 \times 40 \mathrm{~cm})$. 
vidad típica del minimal. En cierta manera, esta potenciación del valor expresivo de la pintura sobre la forma se conecta con la sensibilidad proyectada por el Expresionismo Abstracto $^{11}$.

Para Robert Pincus Witten-Smith ${ }^{12}$, dentro del posminimalismo han aparecido una serie de artistas caracterizados por la excentricidad y habitualidad de las substancias y materiales que usaban, siendo identificadas como "signature substance", este es el caso del fieltro de Barry Le Va, la espuma de Linda Benglis, el plomo de Richard Serra, etc. En nuestro caso, se podría hablar de la madera en María Luisa Fernández. Ana María Guasch afirma ${ }^{13}$, por ejemplo, que el diálogo entre minimalismo masculino y minimalismo femenino quedó patente en las esculturas e instalaciones de P. Apfelbaum, Mona Hatoum, Rachel Lachowicz, Jac Leiner, Claudia Matzko, que utilizaban conceptos propios del minimalismo, como la repetición de formas geométricas simples, pero trabajados con materiales cotidianos, caso de las telas, que en la línea de Eva Hesse eran alterados caóticamente con el afán de feminizar el material del minimalismo o generar un distanciamiento feminista en relación al minimalismo masculino.

Otra manera de alejamiento de las pautas más ortodoxas del minimalismo es la combinación de distintos materiales en una misma obra. En Sin título (Primer Premio del Certamen Gure Artea'85), se confronta la madera, el bronce y el plomo; en Lo semejante. Un dios lo separa siempre, se conjunta la madera y el hierro, al igual que en Mar Rojo II y Mar Rojo III, todas de 1987; en la pieza Entre el amor y el odio, encontramos la combinación del hierro y maderas cubiertas con yeso y óleo; entre otros ejemplos. Esta confrontación de materiales permite generar una mayor atracción perceptiva en el espec-

\footnotetext{
${ }^{11}$ R. PINCUS-WITTEN, Op. cit., p. 12.

${ }^{12}$ Ibídem.

${ }^{13}$ A.M. GUASCH, El arte último del siglo XX. Del posminimalismo a lo multicultural, Madrid, 2000, p. 544.
}

tador, ya que se favorece un sentido claramente expresivo y poético. En piezas donde no se aplica un juego estructural entre las distintas secciones formales, el principal diálogo proviene de la combinación de estos distintos materiales, así como de la combinación de diferentes colores. Para esta escultora, "todo entra dentro de ese mundo emocional. En casos extremos de excesiva intelectualización y conceptualización, he abogado por estos aspectos, pero remarcando que nunca deben estar por encima de los otros. No obstante, prefiero acercarme a las cosas de una manera más emocional que analítica. Me siento más cómoda en esta postura, pero reconozco que ambas son necesarias. No se debe plantear cuestiones manipuladas, ni excesivamente sobrevaloradas" ${ }^{14}$.

Para esta creadora, el instinto es el factor que dirige a los deseos ${ }^{15}$. Igualmente, "los instintos tienen que ver con ese instinto de dominio, de reproducción, lo que se hereda por genes. El instinto es algo que todos tenemos, pero se puede cambiarlo o potenciarlo, y esto es algo peligroso. La cultura refuerza aquel instinto que le interesa, como el de la dominación, pero la cultura no potencia, por ejemplo, el instinto de la cooperación"16.

Volviendo al análisis formal, son numerosas las piezas que mantienen conceptos metafóricos, es decir, diferentes peculiaridades formales y visuales, que consiguen romper la excesiva geometrización y falta de detalles visuales que mantienen las obras del minimalismo más ortodoxo. En esta línea, una de las principales características que va a emplear esta artista es la utilización del rotaflex en las superficies de la madera, generando una peculiar topografía. En este senti-

\footnotetext{
${ }^{14}$ Entrevista realizada a la escultora por el autor en I. SARRIUGARTE, La escultura en el País Vasco en la década de los 80, Serie Tesis Doctorales, Bilbao, 2008, pregunta $\mathrm{n}^{\mathrm{0}} 29$, p. 617.

${ }^{15}$ M.L. FERNÁNDEZ. "Burlas Expresionistas", en AA.VV. María Luisa Fernández. Burlas Expresionistas, Catálogo de la exposición, Madrid, 1993, s/n.

${ }^{16}$ Véase en I. SARRIUGARTE, Op. cit., pregunta $n^{\circ}$ 35, pp. 617-618.
} 
do, muestra una importante caracterización visual y efectista en la obra, ya que el espectador se va a sentir muy atraído por esta peculiaridad. Destacan especialmente trabajos como Sin título $(79 \times 85 \times 17)$, Sin título $(107 \times$ 79 x 40) y las vigas dispuestas en el suelo de su serie Leyenda, siendo todas estas de 1986, así como Lo semejante. Un dios lo junta siempre (Fig. 1) y Mar Rojo III, ambas de 1987.

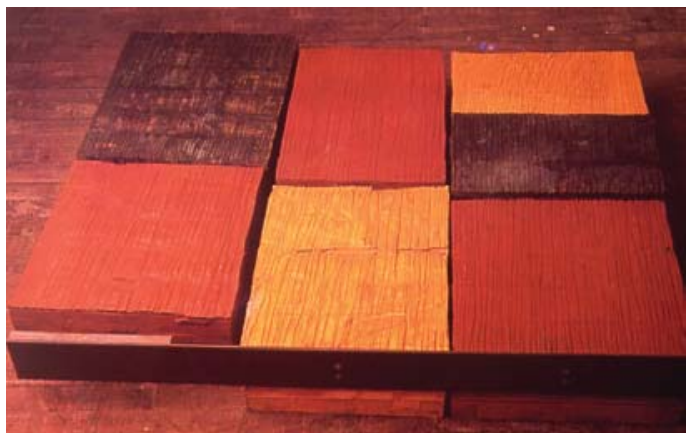

- Fig. 1. Lo semejante. Un dios lo junta siempre 1987. M. L. Fernández, Catálogo de la Exposición, Galería Oliva Mara.

Por otra parte, en la serie Leyenda, encontramos piezas circulares apoyadas en el suelo con la característica de una pequeña incisión en una de las partes, así como también otras piezas circulares con numerosas incisiones concéntricas (Fig. 2). Como asevera Aurora García ${ }^{17}$, los objetos de María Luisa se distancian de las llamadas estructuras primarias o estructuras mínimas, entre otras cosas, porque María Luisa no se inclina a conseguir la ambigüedad a través de la confrontación de unas formas puras en un espacio contaminado de impurezas como el que vivimos, sino que ella misma contamina sus geometrías, haciendo que transpiren accidentes, dislocaciones, relaciones de difícil equilibrio, superficies holladas de múltiples presencias y, a la vez, que el color se funda con la materia. De hecho, como bien apunta Francisca Pérez Carreño: “Nuestro conocimiento del mundo y nuestra percepción del mundo de objetos no es la construcción de una imagen unitaria a partir de percepciones parciales que recomponemos idealmente,

\footnotetext{
${ }^{17}$ A. GARCÍA, Op. cit.,s/n.
}

sino que percibimos objetos y tenemos consciencia de ellos porque los compartimos con otros" $^{\prime 18}$.

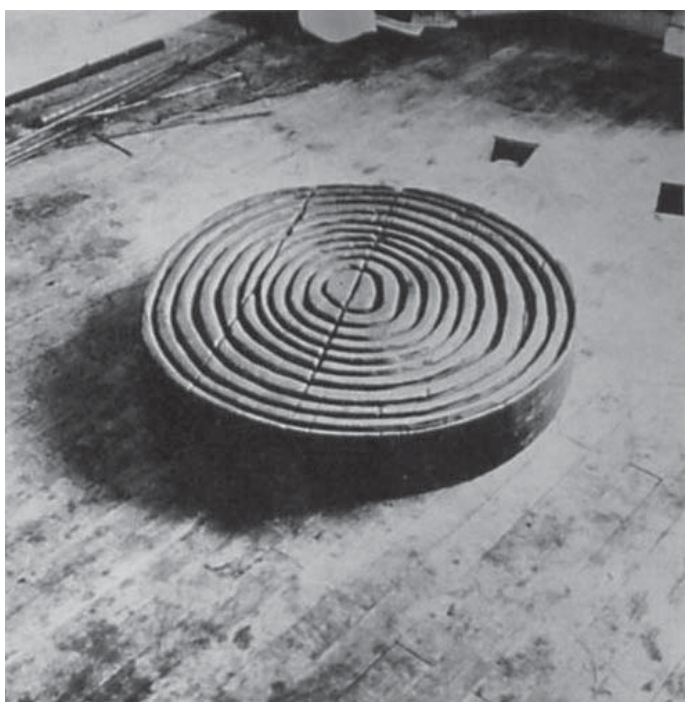

- Fig. 2. Sin título - 1986. CVA-M. L. Fernández. Catálogo de la Exposición, Caja de Ahorros Municipal de Bilbao.

El empleo de estos recursos, es decir, la utilización de diferentes colores en distintas secciones, la combinación de distintos materiales y la aplicación de diferentes rasgos de carácter formal y visual, como la topografía producida por la utilización del rotaflex en las superficies de la madera, permiten romper las referencias más ortodoxas del arte minimal, ya que proyecta una serie de características innecesarias en principio para la existencia de la obra minimalista. En definitiva, son piezas que rompen la simplicidad y la monotonía, trasgrediendo el sentido "del todo es más importante que las partes" o como lo definió Donald Judd: “El problema principal es mantener el sentido del todo ${ }^{\prime 19}$. Este tipo de tratamientos y atributos estéticos altera la identidad inicial de la pie-

${ }^{18}$ F. PÉREZ CARREÑO, Arte minimal. Objeto y sentido, Madrid, 2003, p. 169.

${ }^{19}$ Citado en S. MARCHÁN FIZ, Del arte objetual al arte de concepto, Torrejón de Ardoz, 1986, p. 100. 
za, generando un notable alejamiento de las formas más frías ${ }^{20}$.

DESARROLLO DE LA OBRA ARTÍSTICA (1986-1993)

Encontramos una primera etapa conjunta con Juan Luis Moraza en el colectivo CVA, que se desarrolla desde 1979 hasta 1986 aproximadamente. Para María Luisa Fernández, el hecho de permanecer vinculada a CVA no limitó la producción personal de cada miembro. Simplemente, fue un pacto donde todo lo que se producía era CVA. En este sentido, podía haber trabajos conjuntos, como individuales, pero tanto unos como otros estaban bajo la firma de CVA. De esta manera, se intentaba negar la firma personal y afianzar el anonimato mediante estas siglas ${ }^{21}$.

Después de la disolución de CVA, las siguientes propuestas que realiza se presentan directamente con su propia firma. Respecto a este segundo periodo, que abarca desde mediados de los 80 hasta la actualidad (aunque nosotros solo analizaremos sus obras hasta 1993), una de las características fundamentales en su investigación, sobre todo en los años 80 , será el trabajo con la madera, así como la utilización del color en las diferentes obras. Sobre este punto, comenta lo siguiente: "Yo creo que mi tendencia hacia el trabajo con la madera comenzó a forjarse en los años 80 no tanto por provenir de un contexto tan rural, sino más bien como un acercamiento a determinados artistas castellanos, como Alberto Sánchez. De hecho, aunque no conocía mucho su obra surge

${ }^{20}$ Aquí empleamos el término "frío" en referencia a las esculturas minimalistas caracterizadas por la falta de peculiaridades poéticas y expresivas. Esta definición es empleada en E. ALAMINOS, "Minimal: Máximo de selección, mínimo de elección”, Bellas Artes, nº 9 (61), 1978 , p. 43.

${ }^{21}$ Para más información sobre este apartado, véase I. SARRIUGARTE GÓMEZ. “Experimentar con el arte hasta el límite: el colectivo CVA", Bidebarrieta. Revista de Humanidades y Ciencias Sociales de Bilbao, no 20, 2009, pp. 167-193. como un intento de asimilar un proceso que reconocía más la procedencia de un pueblo. Además, me encantaba trabajar en el estudio y unido a esa imposibilidad de tanta profundización teórica pasaba numerosas horas de trabajo con la madera, ya que era un material más blando donde podía pasar horas experimentando e insistiendo en ella. Retomaba en la superficie de la madera un proceso parecido al acto de arar y cosechar. Además, encuentras personajes que también trataban y abordaban la madera de una manera muy abierta" ${ }^{\prime 22}$. En esta misma línea, María Luisa Fernández nos traslada el siguiente comentario: “Lo más importante no es que sea de pino, lo más importante de las obras hasta los Artistas Ideales de Vitoria era que estaban construidos con tarima machihembrada. Es fácil construir tanto planos como volúmenes con ella"23.

En cualquier caso, la madera de pino aporta unas características y propiedades inherentes, que son notoriamente enfatizadas por la escultora. Elige este material porque independientemente de la forma que adquiera, le permite jugar con las peculiaridades de la textura, caso de linealidades y rasgaduras con incisiones. Hace uso de superficies de madera sin ser sometidas a procesos de lijado y refinamiento. Sobre la textura y la rugosidad dice que "el proceso es como el que realiza un labrador en un determinado terreno. Preparaba el material, echaba los pigmentos, los extendía y marcaba la superficie con el rotaflex. Era un proceso largo" 24 .

Estas propuestas mantienen ciertas referencias con la obra de Alberto Sánchez, de hecho, este escultor castellano desarrolló distintos trabajos en madera y yeso, donde ejecutaba numerosas incisiones lineales en la superficie del material, caso de Escultura de Horizonte, de 1930-1932; Signo de mujer rural

\footnotetext{
${ }^{22}$ Véase en I. SARRIUGARTE, La escultura en el País Vasco..., pregunta $\mathrm{n}^{\mathrm{0}}$ 7, p. 613.

${ }^{23}$ Extracto de un comentario transcrito por la propia artista en un email que nos remite a fecha de 19/09/2013.

${ }^{24}$ Véase en I. SARRIUGARTE, La escultura en el País Vasco..., pregunta no ${ }^{\circ} 12$, p. 614 .
} 
en un camino lloviendo, de 1931-1933; Volumen que vuela en el silencio de la noche y que nunca pude oír y Monumento a los pájaros, ambas de principios de los años 30.

Este tratamiento de la madera en la obra de María Luisa Fernández con referencias a un mobiliario vetusto, rural y antiguo, y caracterizado por las diferentes rugosidades, acentúa el recuerdo de un tiempo pasado. A su vez, estas huellas, como bien afirma Xabier Sáenz de Gorbea ${ }^{25}$, remiten a una acción desarrollada, que anota el hervor del tiempo del trabajo. En este sentido, se interesa por cuestiones como la perdurabilidad, la trasgresión, la alteración y la evidente transformación del material. Evidentemente, conocemos que la educación de esta creadora proviene de un ámbito rural, lo que caracteriza parte de su obra, ya que gran parte del utilitario y los objetos que se encuentran en ese medio son de madera. Obviamente, encontramos otros materiales, pero bien es cierto que la madera predomina sobre el resto. La artista explica la utilización de este material de la siguiente forma: “... como recuerdo, como una forma de hacer que me gustaba y que conocía por mi vida anterior, mi educación en el campo, con todas estas faenas que se hacían.

Sometía cada forma que encontraba o construía al mismo proceso: una especie de memoria del cultivo y el cultivo mismo. No quería una representación del campo ni una abstracción. Era algo concreto. Me sentía a gusto teniendo una norma a la que sujetarme y que además me daba una aparente tranquilidad. El material me encantó desde que cogí el primer trozo de madera. Lo seguí haciendo hasta que se agotó" ${ }^{26}$.

Como ya hemos dicho, las referencias a la obra de Alberto Sánchez son visibles, no sólo por el tratamiento de las incisiones que

${ }^{25}$ X. SÁENZ DE GORBEA, Colección Pública. Selección de Ingresos de Arte Contemporáneo (1985-1990). Catálogo de la exposición, Vitoria-Gasteiz, 1991, p. 130.

${ }^{26}$ Entrevista realizada a la escultora por M. AGUIRIANO, "María Luisa Fernández", Zehar, nº 7, nov-diciembre, 1990, p. 4. realiza el escultor castellano en sus trabajos, en clara referencia a los surcos, que hacen en la tierra los bueyes con los arados, sino porque continuamente este artista también se remitía al campo, como lugar que disponía de distintas formas y materiales. De hecho, Alberto Sánchez afirmaba lo siguiente: "Me dicen: la ciudad. Y yo respondo...: el campo. Con las emociones que dan las gredas, las arenas y los cuarzos: con las tierras que almagra alcalaínas, oliendo a mejorana..... Esculturas de los troncos de árboles descortezados del restregar de los toros, entre cuerpos de madera blanca como hueso de animales antediluvianos, arrastrados por los ríos de tierras rojas y figuras como palos que andan envueltos en mantas pardas de Béjar, tras sus yuntas dibujan surcos......."27.

Esta escultora se aleja de los materiales más industriales, con los que solían trabajar compañeros más cercanos, como Txomin Badiola, Ángel Bados y Peio Irazu. La avalancha de nuevos materiales, los objetos o incluso los materiales provenientes de la industria, del desecho y el reciclaje actual parecen ausentarse de las principales preocupaciones de la artista, ubicada de una manera más sentimental en los procesos programáticos de la madera, como fórmulas que aprehenden cuestiones de la memoria y el pasado y que permiten trabajar con un material más cercano sentimentalmente. La propia producción industrial conlleva procesos de mecanización y deshumanización, por este motivo, la frialdad anímica y emotiva que pueden llegar a transmitir estos materiales le quedan lejanos. La fidelidad de María Luisa con este material ha sido constante $\mathrm{y}$, de hecho, las propuestas que emplea con otros materiales, como el bronce o el hierro responden más a cuestiones de interrelaciones, de intercambios comunicativos y comparaciones. A pesar de que María Luisa Fernández mantuvo una serie de importantes vivencias con este grupo

${ }^{27}$ A. SÁNCHEZ, "Palabras de un escultor", en AA.VV. Alberto Sánchez 1895-1962. Dibujos. Catálogo de la exposición, Bilbao, 1997, p. 157. 
de artistas, abordó un tratamiento plástico claramente alejado respecto a lo que estaban haciendo sus compañeros. El hecho de trabajar con la madera y sus formas fue una condición que muestra su necesidad e interés de alejamiento respecto a las posturas más oteizianas que se pudieron plantear en aquellos momentos.

Entre las diferentes obras de los años 80 , encontramos una especie de subgrupo con diferentes piezas que mantienen una posición horizontal, con formas similares a tablones adosados y listones planos de poca altura y formas de cajones. Así como vigas de madera en posición horizontal. En la obra, que ganó el Primer Premio en el Certamen Gure Artea (Fig. 3), de 1985, pieza que presenta de manera individual y no como CVA, se realiza un objeto parecido a una mesa de madera con cuatro elementos sustentantes. Bajo uno de estos, se sitúan dos piezas, una de bronce y otra de plomo.

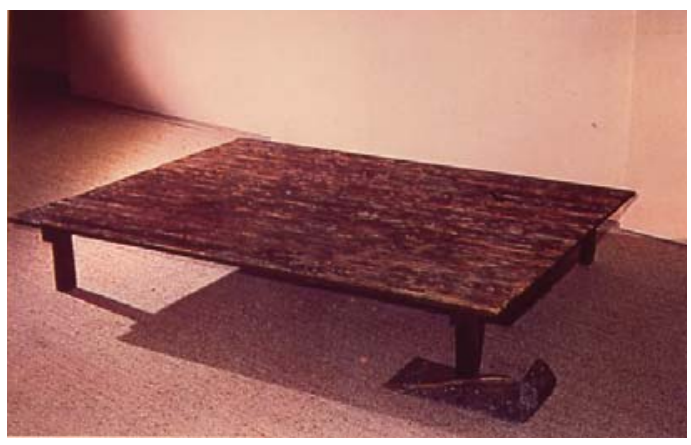

- Fig. 3. Sin título - 1985. Gure Artea 85. Catálogo de la Exposición, Gobierno Vasco.

Esta pieza proporciona una notable presencia horizontal, que además se ve pronunciada al mantener unas patas muy bajas respecto al suelo. Esta impresión de horizontalidad se acerca a la obra de Carl Andre y potencia la capacidad del suelo como soporte escultórico. Esta tendencia a la planitud se proyecta también en el año 1993, con la instalación Burlas Expresionistas, ya que en este caso para desarrollar la serie de Artistas Ideales se sitúa un soporte horizontal: un colchón de goma-espuma en el suelo, como parte de la obra y ampliación de esta mis- ma referencia perceptiva. Anteriormente, en el Aula de Cultura de la CAM de Bilbao, en 1986, realiza la serie Leyenda con obras denominadas Sin título, de carácter planimétrico y claramente horizontales respecto a la superficie del suelo.

Esta referencia de lo horizontal se aprecia con claridad en la obra Lo semejante. Un dios lo junta siempre, de 1987, compuesta de seis bloques planimétricos pintados de diferentes colores. La escultora se sirve de 3 colores fundamentales: verde, rojo cadmio y amarillo. Los bloques mantienen unas dimensiones parecidas y se colocan de forma rectangular. Asimismo, van unidos por una lámina de hierro, mientras que dos de los bloques mantienen una elevación superior al resto. En general, el conjunto proyecta la sensación de varias cuadrículas unidas. Para Lynn Zelevansky, en el posminimalismo se dan "formas minimalistas que a menudo se asocian con la racionalidad (cuadrículas, modulaciones, etc.) - el lado del sentido, combinadas con un sentimiento personal, manifestado en la comprensión visual de la sutileza, la intelectualidad del sujeto y las distinciones estéticas" ${ }^{28}$.

En esta obra, los diferentes bloques de madera se disponen valiéndose del ensamblaje de listones de pino, recortados para formar tarimas. Las tablas están encaladas y clavadas unas con otras y van originando módulos geométricos, que, en algunos de sus casos, presentan un relieve, una especie de superficie con diferentes gestos y calidades de textura, conseguidas con el rotaflex, situándose esta peculiaridad superficial en la parte de arriba, ya que de hecho es la mejor zona de observación. Esta sensación rugosa en los accidentes de la materia resalta la superficie de la madera. La atracción visual de la obra se centra no sólo en la propia topografía de la superficie de la lámina, sino en la elevación de dos de los bloques respecto a los demás, la colocación y la separación desigual entre todos estos.

\footnotetext{
${ }^{28}$ L. ZELEVANSKY, Op. cit., p. 316.
} 


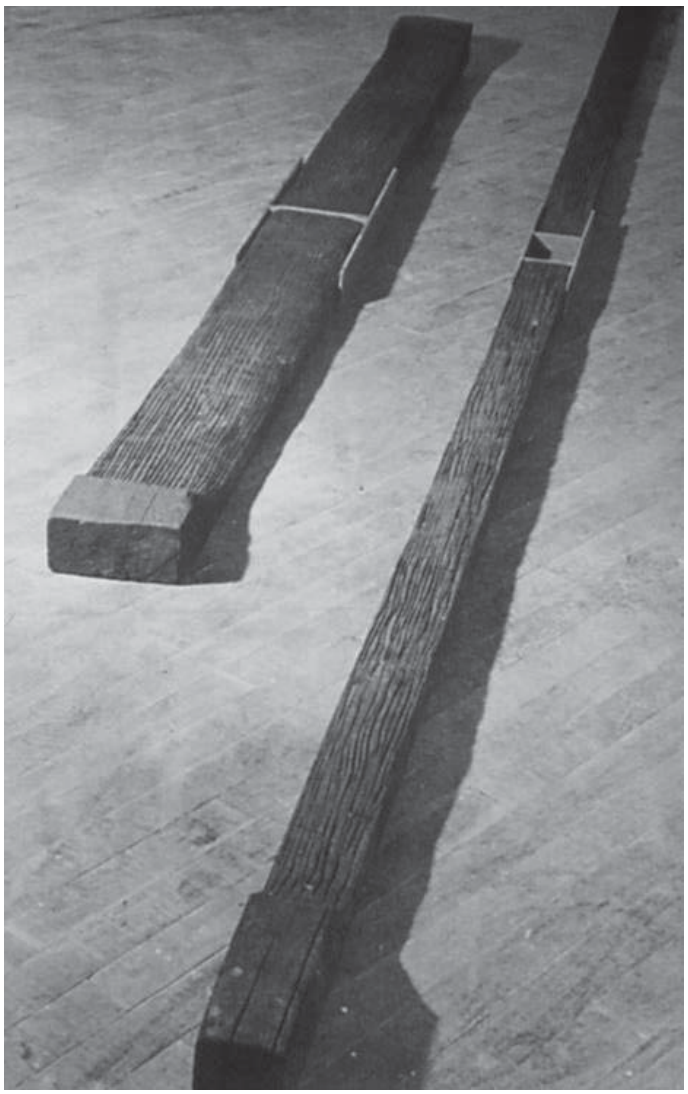

- Fig. 4. Sin título - 1987. CVA- M. L. Fernández. Catálogo de la Exposición, Caja de Ahorros Municipal de Bilbao.

En un conjunto de obras de 1986, pertenecientes a la serie Mar Rojo, volvemos a observar el carácter físico de la madera en su potencialidad visual. Por ejemplo, en Sin título $(250 \times 30 \times 27 \mathrm{~cm})$, de 1986, nos encontramos con dos vigas de madera apoyadas sobre un bloque de hierro. Se vuelven a producir cuestiones de planitud, ya que las vigas conjugan esa idea de horizontalidad y extensión en el espacio. Las dos están paralelas y mantienen un juego espacial, tanto por la disposición de separación entre ambas, como por la elevación sobre el suelo. Igualmente, bajo cierta similitud con estas anteriores, encontramos las piezas con la denominación Sin título (Fig. 4), dentro de la exposición individual CVA-María Luisa Fernández, realizada en el Aula de Cultura de la CAM de Bilbao, en 1986.
En otra de sus esculturas de ese mismo año, que la denominaremos Sin título $(79 \times 85 \times 17 \mathrm{~cm})$, de 1986, se nos presenta una pieza de madera con una articulación en forma de cajón. La superficie se vuelve a conjugar dentro del marco de una textura notoriamente marcada por las líneas y las incisiones, siendo pintado todo el conjunto. Se mantiene una coloración diferente en el centro, anunciándonos una zona de carácter mucho más poético. Asimismo, se está mostrando el vacío y el aspecto espacial de la caja. La obra es una caja cuadrangular realizada en madera, que corresponde formalmente con determinadas formulaciones minimalistas, pero al presentarse ciertas connotaciones poéticas lo aleja de las vicisitudes más ortodoxas del minimalismo. Se está jugando con determinados espacios que producen un aire de interiorización dentro del complejo tridimensional. En el caso de esta escultora, los elementos que producen mayor complejidad se mueven en el marco de lo expresivo y no en los entramados más estructurales y compositivos. Aunque las formas son buscadas con cierta intención, la artista interviene posteriormente para enfatizar ciertas cualidades físicas, en definitiva, se está apostando por una fisicidad con claras referencias poéticas.

Resulta interesante la siguiente afirmación de María Luisa Fernández: "En el arte de este siglo, la persona queda excluida de la obra, y por eso sale a veces a borbotones en los expresionismos. El objeto minimalista es el final de esta tendencia objetual que aleja a la persona del objeto. $\mathrm{Y}$ el objeto se vuelve extraño como un fetiche religioso venido de otro mundo pero al mismo tiempo muy cotidiano. Carl Andre decía -trabajo para tener algo que ver-. Yo creo además que trabajo para tener algo que me mire, y algo con lo que mirar. No siento las obras ni como objetos religiosos, ni como cotidianos. No puedo pensar en formas abstractas" 29 .

\footnotetext{
${ }^{29}$ Véase M. AGUIRIANO, Op. cit., p. 6.
} 
A diferencia de todas estas piezas anteriores, también encontramos otro grupo de piezas cuboides de gran volumen y masa, pertenecientes a la serie Mar Rojo. En estas propuestas, se presenta un tipo de investigación basado más en el volumen, la masa y la interrelación de las distintas piezas unidas, caso de Sin título $(143 \times 127 \times 147 \mathrm{~cm})$, donde se disponen una serie de bloques apoyados unos sobre otros, produciendo un mayor desarrollo vertical.

La planitud de cada una de las piezas apoyada sobre otra revierte en una potenciación del proceso más tridimensional y volumétrico de la obra. Cada pieza se forma mediante la combinación de diferentes secciones geométricas de madera. Por lo tanto, con esta serie, se empieza a observar la conformación de esculturas a partir de distintas secciones, tal y como se verá posteriormente en Artistas Ideales, de 1991, en la Galería Berini de Barcelona.

En Lo semejante. Un dios lo separa siempre (Fig. 5), de 1987, se aprecian tanto motivos geométricos en la composición como un dinamismo mediante la combinación de los bloques coloreados. En esta obra, encontramos una superficie con distintas variaciones cromáticas, que propaga una serie de connotaciones expresivas. Conjunta por una parte un bloque de madera, compuesto de listones de pino con un carácter más volumétrico que la pieza de madera que también le acompaña, con color rojo y claras texturas en la superficie y, por otra parte, una pieza de hierro. Estos dos últimos elementos si fueran colocados en el suelo darían una clara sensación de proyección horizontal y planimétrica, pero en esta situación, colocados de manera vertical, se conjuntan perfectamente con el carácter más volumétrico de la primera obra. Evidentemente, esta combinación de materiales y la utilización del color, como la acentuación de la madera permiten sacarla de los contextos más minimalistas.

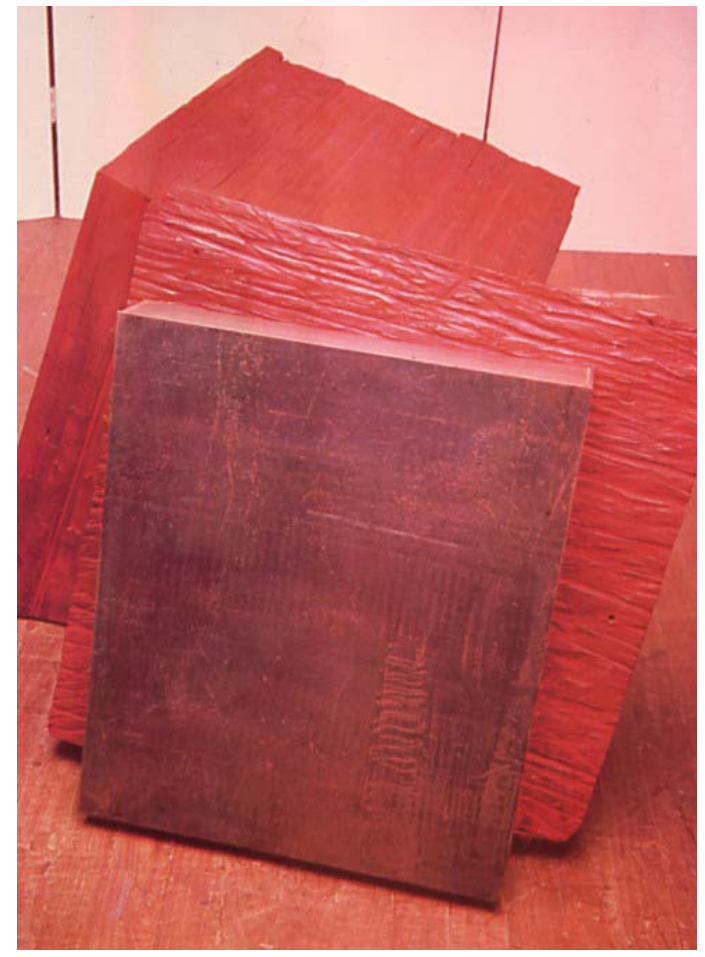

- Fig. 5. Lo semejante. Un dios lo separa siempre 1987. M. L. Fernández. Catálogo de la Exposición, Galería Oliva Mara.

También, emplea el yeso junto con la madera, el hierro y el óleo con el objetivo de generar una mayor ampliación discursiva. Este es el caso de la pieza Entre el amor y el odio (Fig. 6), de 1987. La placa de hierro del suelo emerge por el lado contrario a donde sobresale el bloque de madera, creando un juego de contrabalanceo, donde se plantea el tema del equilibrio. Manel Clot afirma lo siguiente respecto a estas piezas: "la obra de María Luisa Fernández remite siempre la idea del lugar que se invoca al construir, un lugar en el que se erigen las nociones del comportamiento, en el que se levantan estructuras en espiral, en el que se cimentan las relaciones con el espacio y la mente, en el que se produce la fusión de lo poético y lo material, lo psíquico y lo físico, lo presentacional y lo representacional, lo condensado, lo político" ${ }^{\prime 30}$.

${ }^{30}$ M. CLOT, "Tránsitos, estancias, innombrables (la casa natal)", en AA.VV. María Luisa Fernández. Catálogo de la exposición, Barcelona, 1991, p. 10. 


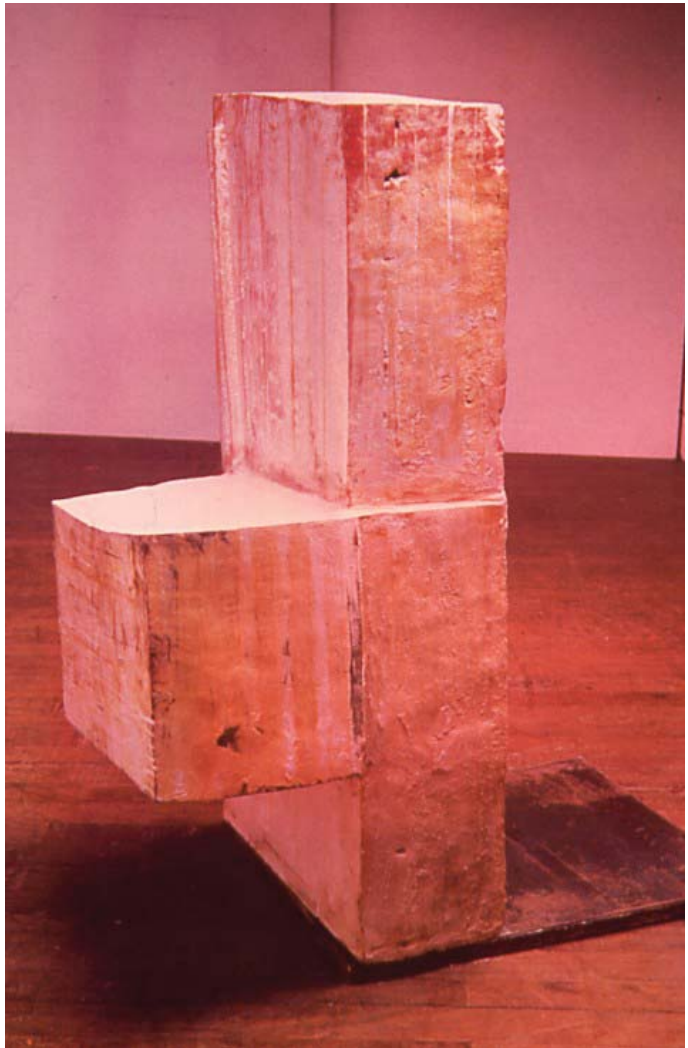

- Fig. 6. Entre el amor y el odio - 1987. M. L. Fernández. Catálogo de la Exposición, Galería Oliva Mara.

Dentro de esta encrucijada de discusión plástica sobre el volumen, también encontramos Mar Rojo I (Fig. 7), de 1987, compuesta de 3 cubos de madera adosados en tres posiciones diferentes, de hecho el conjunto aparece como una sucesión en movimiento de estos 3 cubos. Las principales referencias de este trabajo perfectamente podían proceder de la obra de Jorge Oteiza, en especial, de los cuboides abiertos Malevitch, que unidos o fusionados forman la serie de las maclas. En este sentido, J.Oteiza creó un sólido nuevo, donde partes y unidad no aparecen estables, produciendo una circulación interna. No obstante, a diferencia de las obras de María Luisa Fernández, los bloques permanecen abiertos, lo que notifica la actuación del espacio sobre la obra. Otras propuestas donde se da con claridad la presencia volumétrica han sido Lo semejante. No necesita de su igual y Lo semejante. Necesita de su igual, ambas de 1987.

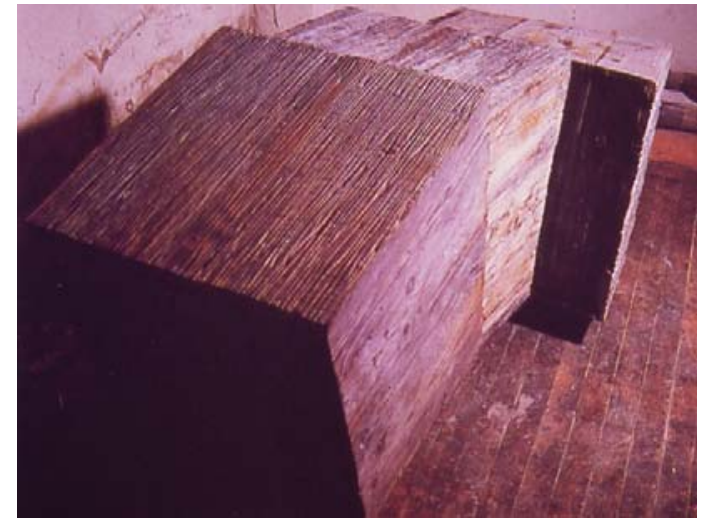

- Fig. 7. Mar rojo I, 1987. Itinerario. Seis escultores. Catálogo de la Exposición, Sala Amadís.

Por otra parte, también observamos propuestas que mantienen una mayor preocupación por el carácter más estructural, con la articulación de distintas secciones y planteamientos del vacío, espacio, planos y líneas. Son obras que proyectan una mayor correlación formal con ciertos trabajos de Txomin Badiola, Peio Irazu, Ángel Bados y Juan Luis Moraza, como Pieza insatisfecha (1987) y En silencio (1988), de Peio Irazu y Molde para la oscuridad. Lithos (1987-88), de Juan Luis Moraza.

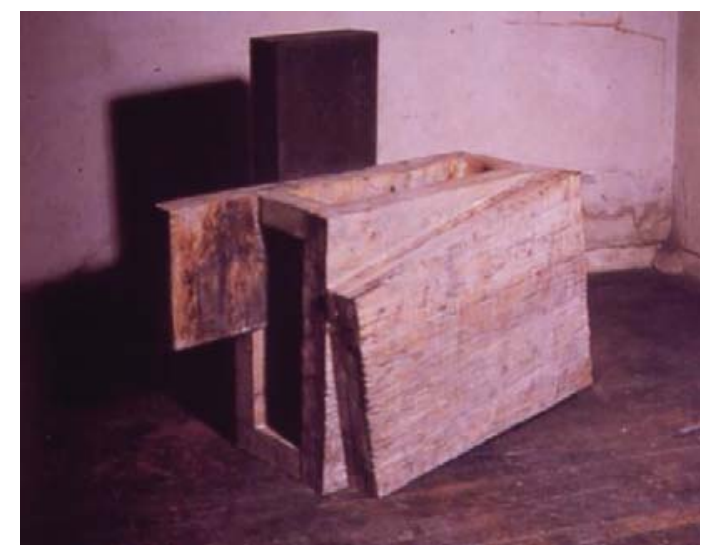

- Fig. 8. Mar Rojo II - 1987. Itinerario. Seis escultores. Catálogo de la Exposición, Sala Amadís.

En sus propuestas, aparecen diferentes elementos unidos, que producen interesantes interrelaciones, generando una clara estructuralidad formal. Este es el caso de Mar Rojo II (Fig. 8) y Mar Rojo III, ambas de 1987. La artista plantea conjuntar diferentes 
partes con el propósito de producir secciones salientes y entrantes en la obra. Esta articulación de unidades que producen un conjunto estructural se ve reforzada por el juego de las líneas e incisiones de los listones.

También, se aplican otros materiales que producen una mayor estructuración en el conjunto de la obra, como es la incorporación del hierro. En el caso de Mar Rojo II, una de las secciones se dispone inclinada respecto a uno de los planos colocados de manera vertical, lo que potencia la dinamicidad del conjunto. Otra de las partes sobresale en la dirección que se sitúa el bloque de madera, creando otra línea de clara aplicación estructural y dinámica. Asimismo, la propia disposición vertical del bloque de hierro da una sensación de mayor realce a este mismo elemento, en contraste con la caja de madera, que se asienta sobre su lado más alargado, generando una clara diferenciación entre la posición de los dos materiales. En general, emplea desarrollos geométricos, con diferentes planos, vértices y líneas direccionales, con sus puntos de tensión, en un sentido claramente estructural.

Entrados en los años 90, debemos destacar principalmente la instalación realizada en 1991 en la Galería Berini en Barcelona y Burlas Expresionistas en la Galería Trayecto de Vitoria, en 1993, año en el que dejamos de realizar este seguimiento artístico a la escultora.

Durante estos años, la artista retoma una faceta que anteriormente no había sido tan trabajada al desarrollar pautas más teóricas junto con su obra, por ejemplo, mediante el texto Burlas Expresionistas en la instalación del mismo título. En estos trabajos teóricos, las cuestiones sociales y el comportamiento del artista son elementos primordiales y protagonistas. Para la artista, en estos años, se acrecienta una visión crítica, que anteriormente no se había dado con tanta intensidad, en comparación a como lo había llevado a cabo Juan Luis Moraza, su compañero en CVA. Aunque esta fase crítica le llega más tarde, durante esta instalación se asienta só- lidamente el modo de abordar una cuestión tan problemática y complicada como ésta.

En la instalación de 1991, se dan cita obras de 1990 y de este mismo año, caso de su serie Artistas Ideales y los Burladeros, que volverán a aparecer en la siguiente instalación. En relación a esta primera serie, cada obra mantiene un título diferente como Bella Interesante, Conciso claro, etc. En definitiva, podemos observar bloques de madera circulares que en algunos casos se encuentran sin algunas de sus partes, mientras que en otros casos aparecen con todas sus secciones. Para Manel Clot, estas formas son "una particular configuración inicial tendente hacia lo vertical, una configuración irreductible que parece corresponderse con la experiencia corporal, hablando sólo de sus estatutos físicos, sin por ello caer jamás en las simples correspondencias anatómicas, es decir, huyendo de esas posibles aproximaciones antropomórficas antes citadas, ésas que anidan en la casa de la representación" ${ }^{31}$.

De acuerdo a María Luisa Fernández, "los Artistas Ideales de la exposición de Vitoria no están construidos con tarima, están tallados de tablones de madera maciza, también de pino, y pintados con óleo blanco creando una piel con textura" ${ }^{32}$. El hecho de que todas estas obras estén tratadas con un mismo color, tiende a homogeneizar el tratamiento de la pieza y nos permite observar la obra como una unidad. En general, se proyecta desde bloques más estructurales a otros más monolíticos. Por una parte, se trata de grandes bloques que por su capacidad volumétrica y de masa conectarían con otras piezas volumétricas realizadas anteriormente, como Entre el amor y el odio, y, por otra parte, en su sentido ideológico conectan claramente con el mensaje de Burlas Expresionistas.

También, para explicar estas piezas de carácter circular, encontramos con anterioridad un referente en la obra Leyenda, presen-

\footnotetext{
${ }^{31}$ Ibídem, p. 9.

${ }^{32}$ Extracto de un comentario transcrito por la propia artista en un email que nos remite a fecha de 19/09/2013.
} 
tada en el Certamen Bizkaiko Artea, de 1986, trabajo que simula una pieza con una superficie a modo de laberinto concéntrico, y que a su vez nos remite a Labyrinth, de 1974, de Robert Morris. A su vez, el bloque de madera da la imagen del paso del tiempo, ya que el tratamiento que se le da, produce la sensación de un bloque antiguo. Los círculos concéntricos, que se sitúan en la parte superior de la pieza de madera, parecen retomar las vueltas que se pueden dar hasta descubrir la verdad subyacente en cualquier leyenda. Esta pieza como cualquier leyenda relatada no conduce directamente al punto central (conocimiento real y verdadero), sino que para llegar a este punto hay que dar diversas vueltas sobre este mismo punto.

En la exposición CVA-María Luisa Fernández, de 1986, y dentro de la serie Leyenda, realiza una obra similar. A diferencia de la primera, que tiene 3 líneas horizontales, que cortan la superficie de la obra, esta segunda dispone de 9 líneas paralelas, que cortan las incisiones circulares. Además, la obra se dispone rodeada de una lámina de hierro circular que sobresale en altura respecto a la pieza de madera. Igualmente, en esta exposición, se pudieron observar diferentes propuestas, como Sin título, es decir, piezas circulares y planas, que se disponen juntas, con una incisión o corte diferente en una de las partes. También encontramos una pieza circular que no tiene nada en su interior. También, en esta misma exposición, aparecen varios dibujos con formas circulares. Todos estos trabajos denominados Sin título pertenecen a la serie Leyenda. Por otro lado, debemos comentar que en Burlas Expresionistas aparecen los Ensayos, dibujos realizados en papel sobre cartón, que representan laberintos con recorridos de animales simulados.

Estos trabajos tienen referencias con el tema de los laberintos ${ }^{33}$, ya que estos tam-

${ }^{33}$ Otros artistas también han tratado este tema. Debemos recordar que María Jesús Cueto, Nieves Larroy, Antonio Achucarro e Inma Jiménez (profesores de la Facultad de Bellas Artes de la Universidad del País Vasco) realizaron un proyecto de investigación, becado por bién guardan un secreto metafóricamente en el centro, en este sentido, el mismo arte es como un camino hacia ese centro. María Luisa retomará posteriormente, en 1996, de manera teórica la cuestión de la búsqueda en relación con el laberinto ${ }^{34}$. El texto $Y$ después del laberinto ¿Qué? tiene una connotación notablemente crítica, ya que según ésta siempre se obliga al artista a mantener una constante actitud de búsqueda en su vida profesional, abogando esta escultora por la propia libertad de movimiento y decisión del artista, sea cual sea. Debemos recordar que María Luisa Fernández ha realizado su tesis doctoral sobre El Laberinto, donde no sólo se analizaba el laberinto como una figura, sino la posibilidad de empezar a crear otra figura más adecuada que la del propio laberinto. Debemos recordar que el ser humano crea maneras de estar en el mundo, maneras que definimos como cultura. Por este motivo, se plantea la posibilidad de pensar otras figuras, que nos sirvan de modelo, y que obviamente estén menos ligadas a modos de coacción, incertidumbre y jerarquía, aspectos que en muchos casos sirven para definir nuestra situación cultural.

La artista da un toque de atención para no caer en el hábito y la inercia de encerrarse en el laberinto del arte. En el texto $Y$ después del Laberinto ¿Qué?, la escultora viene a sugerir la situación laberíntica y personal

esta misma universidad, con el título Génesis creativa: El laberinto, expuesto en la Sala de Exposiciones del Conservatorio Municipal de Sestao, del 16 de septiembre al 12 de octubre de 1996. Se trata de un proyecto de introspección sobre el tema del laberinto, planteado desde diversas perspectivas, tanto del campo teórico como del creativo plástico. Por ejemplo, M.J. Cueto en KnósosSestao plantea el laberinto como totalidad, metáfora y representación cosmológica; Nieves Larroy en Entrada y salida lo aborda como juego y símbolo; Antonio Achucarro en Centros analiza la ciudad como laberinto; y por último Inma Jiménez en Laberinto de Sestao, el cuerpo, la imaginación, la mente y el alma lo plantea como lugar de transformación. Para más información, remitirse a AA.VV, Génesis creativa: El laberinto. Catálogo de la exposición, Sestao, 1996.

${ }^{34}$ Este tema se trata en M.L. FERNÁNDEZ, "Y después del laberinto ¿Qué?", Zehar, no 31, 1996, pp. 36-38. 
del creador, que se encuentra cotidianamente buscando la solución de ciertas problemáticas personales impuestas o inducidas por la cultura ortodoxa.

Critica que el arte sea como un laberinto, es decir, un intento forzado de tener que llegar a una supuesta búsqueda personal (centro del laberinto), para luego salir de ahí y es aquí cuando esta escultora se pregunta y luego qué. Para María Luisa Fernández, la aparición de esta especie de expectante idea y actitud está planteada y bien ensayada, siendo en el fondo una propuesta meramente manipuladora, en definitiva, una técnica que acaba convenciendo de su inocencia, pero que, de hecho, acaba predeterminando al artista.

Aboga por alejarse de esta fatal lógica impuesta por el laberinto, que no hace más que mantener al artista en la posición que el propio laberinto quiere, sin posibilidad de libertad real en decisión y movimiento. Según la propia creadora, para lo institucional resulta claramente interesante mantener a los artistas en el propio mecanismo y proceso de la vorágine del laberinto, en vez de dedicarse o enfocarse en otras cuestiones más prácticas y profesionales.

Entre los diferentes engaños que encuentra esta creadora, uno de ellos resulta la entrada repetitiva en el laberinto y su supuesta resolución problemática. En este sentido, comenta que "el laberinto domestica el hábito, educa el -yo- en su tragedia, en el aprendizaje de su incertidumbre. En el hábito del laberinto, naturalizado, aprendido hasta la saciedad, como ratas de laboratorio que con el tiempo acaban sabiendo perfectamente (después de muchos sacrificios), el camino a seguir para llegar a la meta recompensa. El laberinto educa el inconsciente de tal modo que tal inconsciente, ya educado, haga del laberinto una sustancia" ${ }^{\prime 35}$.

Una de las series más importantes que ha desarrollado esta artista es la de los Burladeros, que aparecen en esta misma instala-

\footnotetext{
${ }^{35}$ Ibidem, p. 37.
}

ción. El concepto de burladero mantiene un carácter de frontera y límite ${ }^{36}$, ya que de hecho se trata de una barrera física, que se impone en el espacio, es decir, hay un ante y un post espacial. Estos Burladeros se componen de distintos listones de madera unidos, que son pintados. Su aspecto y dimensión, junto a toda una serie de planteamientos pictóricos, produce una notable impresión en el espectador. Emplea desde numerosos colores vivos a otros caracterizados por dos colores únicamente: el blanco y el negro.

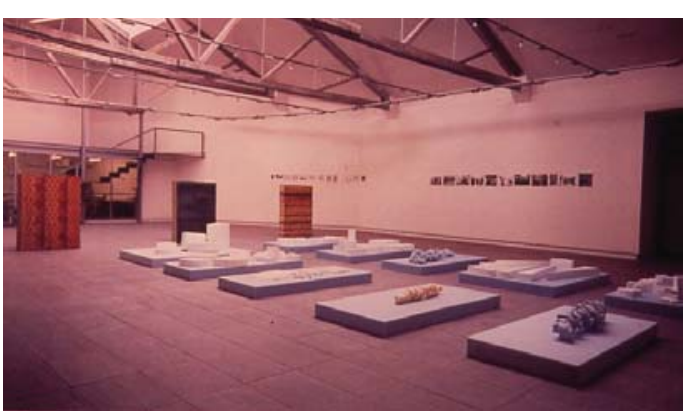

- Fig. 9. Instalación Burlas expresionistas (vista general) - 1993. M. L. Fernández. Catálogo de la Exposición, Trayecto Galería.

Respecto a la instalación Burlas Expresionistas (Fig. 9), realizada en el año 1993, en la Galería Trayecto de Vitoria, debemos resaltar la existencia de numerosas referencias significativas, ya que la diversidad de procedimientos tridimensionales, pictóricos y fotográficos proporcionan un marco muy amplio para las cuestiones interpretativas.

En medio de la instalación, se encuentran 10 colchones de goma-espuma y, sobre estos, diferentes unidades, piezas, porciones y elementos de madera y poliuretano pintados

\footnotetext{
${ }^{36}$ Recordemos que el tema del límite fue ya tratado en CVA. Este colectivo presentó diferentes propuestas bajo el soporte de la pintura, desarrollando el tema de los límites. También, el estudio del marco y los pedestales lo relacionaron con la problemática del límite, principalmente desde 1980 a 1983. Para éstos, el problema de los límites desplazaba al de la estructura y se convertía en tema y modo para el arte. Igualmente, CVA proponía el acercamiento al límite, como medio que generaba nuevas perspectivas de trabajo. Este paso será definido como un estadio que conduce e invita al espectador y al mismo artista a una transformación.
} 
en blanco no-neutro, que representan la obra de los Artistas Ideales y, en el otro lado, los Burladeros. Asimismo, en las paredes, hay diferentes fotografías, donde aparecen diferentes críticos y artistas neoexpresionistas y de la transvanguardia italiana. También, encontramos al otro lado de la galería otros trabajos que se titulan Ensayos y una especie de gotas blancas, que simulan una lluvia de semen.

Respecto a los Artistas Ideales, podemos decir que algunos se presentan a modo de columnas vertebrales compuestas de piezas de madera, que se enlazan y se adecuan unas a otras. En algunos casos, aparecen agrupadas y ordenadas creando una forma superior, y en otros casos presentan una desorganización, donde todas las piezas aparecen disgregadas.

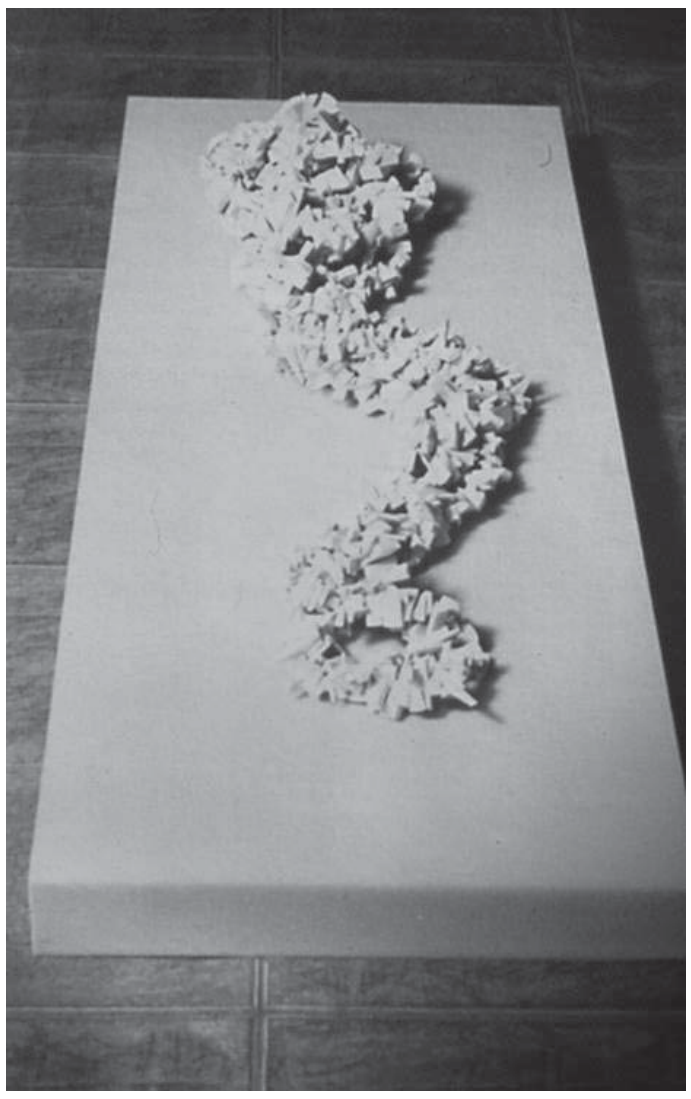

- Fig. 10. Instalación Burlas expresionistas (detalle) - 1993. M. L. Fernández. Catálogo de la Exposición, Trayecto Galería.

Los 10 colchones mantienen piezas con tamaños y formas diferentes (Fig. 10), además, en numerosos casos, las porciones o piezas, que se presentan encima de los colchones, parece que son las secciones que formaban los Artistas Ideales de la anterior instalación. Por otra parte, en los trabajos con el poliuretano se desarrollan aplicaciones más abigarradas y compactas.

Aquí, en este espacio, se ha pasado del anterior artista ideal de carácter más totémico, compuesto de discos superpuestos, a unas nuevas piezas, donde se elimina esta elevación (exceptuando un par de casos) y se apoyan de manera horizontal sobre un colchón.

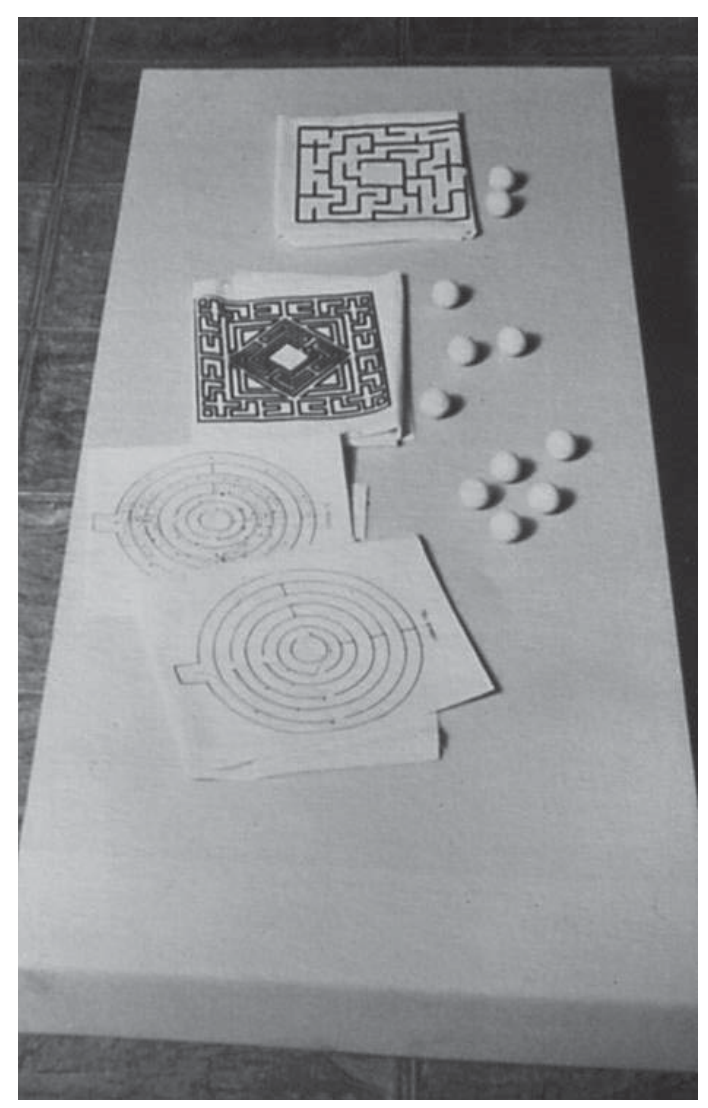

- Fig. 11. Artistas ideales, 1992.

En uno de los colchones (Fig. 11), observamos un tratamiento menos objetual y más cercano a ciertas referencias conceptuales de su etapa en CVA, ya que tenemos diferentes láminas serigrafiadas sobre tela y plástico con diferentes dibujos de formas abstractas, tanto circulares como geométri- 
cas. Dos de estos dibujos responden a una especie de diana y los otros dos a decoraciones geométricas que simulan el laberinto. A su vez, aparecen 11 bolitas pequeñas que recuerdan los trabajos de la exposición CVA/ objetos, de 1984.

Con su obra de los Artistas Ideales, está abordando el engaño y el espejismo que generan ciertos artistas considerados ideales, ya que en el fondo todos sus discursos no son más que pura demagogia. Nuevamente, por lo que está abogando es por volver a recuperar unas pautas, que liberen al artista de caer en espejismos creados por diversas actitudes falsas. Defiende discursos reales, que aborden el verdadero problema que afecta al artista y al arte, olvidando las demagogias de determinados críticos y creadores ideales. Igualmente, en el texto del catálogo, se anota una evidente crítica a determinados artistas neoexpresionistas y, en especial, a Joseph Beuys. En el discurso teórico de los anteriores artistas, se podía atisbar la idea de estar en el centro sin esfuerzo y por naturaleza divina, simplemente por el hecho de su supuesta genialidad, lo que en sí mismo resulta una tendencia conservadora. Para esta escultora, Joseph Beuys es uno de los artistas más carismáticos, de los más recurridos y citados, por su interés en ampliar el territorio artístico. Se muestra como educador de la sociedad, actuando como profeta y chamán. Pero, le crítica que ponga por excusa que hay que educar a una sociedad maleducada, para transformarla según los propios planteamientos del artista $^{37}$. Su reproche va más allá, criticando la acción de Beuys Espinas asadas de primera, de 1970, donde predica sobre 2 aspectos: Nadie tiene que morirse de hambre y todo se come si lo preparas bien. El sentido de estas sentencias resulta para María Luisa Fernández un verdadero engaño, ya que lo que se pretende es introducir y vender una falsa ideología. De hecho, María Luisa Fernández emplea la palabra desperdicio para referirse al discurso de Beuys, ya que no es

${ }^{37}$ M.L. FERNÁNDEZ, “Burlas Expresionistas...”, s/n. más que un residuo ideológico, que se vende como teoría de interés colectivo y social.

Esta escultora transcribe la siguiente descripción: "En la conversación que Beuys mantiene con Spoerri sobre la acción, Spoerri recuerda las críticas que el público asistente le hiciera, y que se referían al grado de cinismo de su propuesta sobre un mercado libre del arte, cuando él estaba completamente implicado en el sistema de mercado más convencional e institucionalizado. Beuys responde que su -alternativa- es para aquellos que no están aún en el mercado. Como él mismo está ya en el mercado, no tiene sentido que esté contra él....Lecciones para que los artistas, los otros artistas, hagan lo que él mismo no hace. De ese modo consigue un doble efecto, complace al mundo del mercado que lo alimenta, y al mismo tiempo satisface su conciencia revolucionaria ofreciendo alternativas que a nadie dañan" ${ }^{38}$.

Según María Luisa Fernández, este tipo de declaraciones y discursos resultan claramente engañosos, ya que no van a solucionar ninguno de los problemas de las personas concretas a las que de hecho van dirigidas sus consejos. Este tipo de discurso educativo y supuestamente alternativo es parte de una legitimización como artista comprometido en unos momentos donde llevar este título es algo realmente importante para aquellos que están en el poder artístico. Es decir, se trata de artistas que abogan por mantenerse en lo establecido y, a la vez, contentar a numerosos artistas con un falso discurso revolucionario.

Se queja de que muchos de estos artistas no hagan arte, simplemente parecen centrarse en tratamientos ajenos a la verdadera práctica artística. A este respecto, dirá por ejemplo lo siguiente sobre Walter Dahn, pero extrapolándolo a todos aquellos que actúan como él: “... pero hay un pequeño problema ¿Quién reconoce en estas personas al artista? ¿Quién, cuánto y por qué se les paga? No hay nada suyo en los museos,

\footnotetext{
${ }^{38}$ Ibídem.
} 
ni en los libros, ni en las revistas sobre arte. No sabemos nada de ellos. Artísticamente no existen, ésos que se supone son los más coherentes, los más radicales de entre los artistas, entre sus alumnos" 39

Esta escultora también critica la exposición Origen y Visión de los neo-expresionistas, artistas que, en definitiva, no mantenían ninguno el verdadero valor revolucionario y comprometido que supuestamente defendían. El compromiso en estos momentos resulta algo testimonial, de ahí que reproche directamente el discurso de creadores como Joseph Beuys. Critica que se presenten determinados compromisos, que no sirven más que para crear una determinada apariencia, pero sin verdaderas soluciones. Hoy en día, se necesitan soluciones reales, por lo tanto, los compromisos y los discursos éticos testimoniales no sirven para una actuación real.

Se buscan verdaderas pautas comprometidas o por lo menos discursos transparentes, que no sean demagógicos para otros artistas, en este sentido, tenemos el ejemplo del pintor neoexpresionista alemán Georg Baselitz, al afirmar de una manera transparente y sincera que "el artista no es responsable ante nadie. Su papel social es asocial y su única responsabilidad consiste en una actitud hacia la obra que crea. No hay comunicación con el público. El artista no plantea preguntas, no hace afirmaciones, no ofrece información alguna. Es el producto final el que cuenta; en mi caso, el cuadro" ${ }^{\prime 0}$.

Respecto al compromiso y el papel del artista actual, para esta escultora, siguiendo el sentido del texto que acompaña el catálogo de la instalación Burlas Expresionistas, cada uno tiene que encontrar el suyo, aunque tampoco sea una necesidad la obligación de tener que buscar un compromiso. Los discursos donde se fomenta que el artis-

\footnotetext{
${ }^{39}$ Ibídem.

${ }^{40}$ Citado por J. HERNANDO CARRASCO, "Del artista comprometido al individualismo postmoderno (años 60-años 80)", en P. RODRÍGUEZ-ESCUDERO (ed.), El papel y la función del arte en el siglo XX, Vol. II (Comunicaciones), Bilbao, 1994, p. 265.
}

ta llegue a ser un creador ideal resultan muy peligrosos, siendo quizás más práctico e interesante, asentar un lugar de referencia en el contexto socio-cultural y asumir la idea de artista de un modo menos restringido.

Por otra parte, para María Luisa el comportamiento de Jorge Oteiza no es muy diferente al de Joseph Beuys. Oteiza propone un nuevo espacio de actuación: el político. Tenemos que tener en cuenta que según Jorge Oteiza una vez concluido el proceso de experimentación artístico, el artista se debe regenerar, retomando otra línea de investigación totalmente diferente. Este debe asumir otro campo de actuación, tal vez más comprometido, como es propiamente el ideológico, el político, o bien, el campo de la educación, ya que una vez que esa conclusión ha aportado diversos descubrimientos, sean metodológicos, existenciales o culturales, estos deben ser puestos en conocimiento del resto de los artistas.

De este modo, este primero se vuelve un educador de otros artistas, empleando diversos medios y herramientas que pueden favorecer supuestamente la creación libre de otros creadores. En resumidas cuentas, para Jorge Oteiza, el artista que ha obtenido una serie de conclusiones en su trayectoria artística debe abandonar el arte, pasando al campo político. De igual manera, Joseph Beuys también utiliza el campo de la educación como medio de trabajo.

María Luisa Fernández reprocha y critica directamente a J.Oteiza por su empeño en fomentar el abandono del creador para dedicarse a otros campos. Esta escultora lo que está intentando defender es que sea el propio artista el que decida cuando y como quiere abandonar, pero que no se lo planteen de una manera tan exigente y confusa bajo el encubrimiento de una supuesta educación y ética, es decir, al final y al cabo, otro falso discurso que no ayuda al artista en sus verdaderos problemas. No obstante, aparte de esta crítica realizada, también reconoce que algunas de las propuestas culturales planteadas por Oteiza han sido muy novedosas 
e interesantes, saliéndose del circuito más ortodoxo, motivo este que las ha condenado al olvido y su no aceptación.

Volviendo nuevamente al análisis formal de la serie Artistas Ideales, algunas piezas recuerdan el tratamiento de otras realizadas en años anteriores, como la serie Melenas, donde los desarrollos formales también son de un reducido tamaño. La diferencia principal se basa en que estos trabajos se presentan de una manera vertical y en esta instalación se plantean de manera horizontal. Los trabajos Melena I y Melena II, de 1988, son una serie de bloques de madera de tamaño reducido, que se agrupan unidos y conformando una unidad de diferentes elementos articulares. Nos encontramos con piezas rectangulares, cuadrangulares, circulares, es decir, una amalgama de diversas variedades tipológicas, que permiten conjugar una mayor diversificación estructural y formal. En este sentido, el color tiende a potenciar un desarrollo homogéneo.

En esta instalación, también podemos encontrar en la pared otros trabajos como Ensayos, de 1992, de medidas variables y realizados en papel sobre cartón. Se trata de diferentes dibujos y en algunos casos gráficos, que representan laberintos con recorridos simulados de animales, así como gráficos relativos a experimentos con animales. El tema de los laberintos y de los Artistas Ideales da salida a un sentimiento de exclusión, que forma parte de su aprendizaje y su manera de estar en el mundo, no en relación a una situación concreta, sino más bien con un problema más general, de cultura. En cierta manera, se estaría relacionando el aprendizaje y las exigencias de nuestra cultura.

María Luisa Fernández había cogido los laberintos de un libro de experiencias en un laboratorio, que se centraban sobre el aprendizaje de ciertos animales, que andaban sobre laberintos y se les obligaba a realizar un recorrido para alcanzar una meta. Estos modelos le sirvieron para comparar la experiencia del laberinto con la situación de la cultura. En definitiva, la serie Ensayos en Burlas Expresionistas habla de pequeños laboratorios o grandes sistemas que obligan a determinadas acciones, es decir, todas esas imposiciones y obligaciones por las que un individuo debe pasar para lograr una meta.

En otra sección de la exposición y sobre una pared, aparecen unas formas a modo de gotas de lluvia de semen. Estas piezas vuelven a aparecer en la instalación María Luisa Fernández. Artistas Ideales, ubicada en la Sala Carlos III de la Universidad Pública de Navarra en Pamplona, en 1997, bajo los títulos de Corrida, Semen y Mo. Para autores como Ana María Guasch ${ }^{41}$, las obras abyectas son aquellas relacionadas con la sangre menstrual y la descarga sexual (como las gotas de semen). En este sentido, la imagen de la mujer sublimada aparece en un contexto donde se mezcla lo obsceno, lo violento y lo abyecto. Las teorías de Lacan fueron fundamentales para el retorno de una realidad traumática, sin velos, sin pantallas protectoras, sin ilusionismos, sin ficciones, una realidad no representada o simulada. Esta misma relación traumática entre el sujeto (la mirada) y el objeto (mundo) se puede también rastrear en las teorías de la psicoanalista y feminista Julia Kristeva, que avanzó a un nuevo concepto: el de lo abyecto, como aquello excluido del orden simbólico. Lo abyecto es una condición que altera la identidad, el sistema y el orden, que no respeta los límites y las reglas.

Al lado de las piezas, que simulan gotas de semen, aparecen 11 cuadros con fotografías de artistas y críticos, que nos van acercando al verdadero interés ideológico de esta exposición. Evidentemente, se está forjando una crítica al carácter falocrático del $\operatorname{arte}^{42}$, enfatizando esta crítica con la representación de fotografías, donde no aparece

\footnotetext{
${ }^{41}$ Para más información, remitirse a A.M. GUASCH, "Una lectura de la posmodernidad: de la simulación al discurso del trauma", en D. HERNÁNDEZ SÁNCHEZ (ed.), Estéticas del arte contemporáneo, Salamanca, 2002, pp. 105-111.

${ }^{42}$ A.M. GUASCH, El arte último del siglo XX. Del posminimalismo a lo multicultural..., p. 540.
} 
casi ninguna mujer artista. Todo esto responde a una serie de experiencias vividas, así como a la situación actual de muchas mujeres creadoras respecto al género opuesto. Se pretende también dar una idea de que el artista ideal lo es primero porque es masculino. Por ejemplo, en tres de estas fotografías podemos ver a las siguientes personas:

1-Fotografía con el río de fondo. De izquierda a derecha aparecen Hans Peter Adamski, Walter Dahn, Naschberger, N.N., Kever, Peter Bömmels y Jiri Georg Dokoupil.

2-Fotografía con el póster de fondo y el nombre de Per Kikerby. De izquierda a derecha aparecen: Michael Werner, Detlev Gretenkort, Per Kikerby, A.R. Penck, Markus Lüpertz, Georg Baselitz y Jörg Immendorff.

3-Fotografía en una sala de exposiciones. De izquierda a derecha aparecen: Sandro Chia, Nino Longobardi, Mimmo Paladino, Paul Maenz, Francesco Clemente y su esposa, Wolfgang Max Faust, N.N., Fantomas, Gerde de Vries y Lucio Amelio. Esta misma fotografía vuelve a aparecer en la instalación María Luisa Fernández. Artistas Ideales, en la Sala Carlos III de la Universidad Pública de Navarra en Pamplona, en 1997. En esta ocasión, la fotografía de gran formato aparece con las caras recortadas de los asistentes y junto a esta, en el suelo, numerosas piezas de escayola, que recuerdan gotas de semen. Debemos recordar la relación existente entre el propio título de la instalación Burlas Expresionistas y el hecho de que la mayoría de las personas, que aparecen en las fotografías, estén relacionadas, como artistas o críticos, con el neoexpresionismo alemán y la transvanguardia italiana.

Finalizaremos el análisis de esta instalación con la siguiente sentencia de Xabier Sáenz de Gorbea, extraída del texto Lógica de la provisionalidad, al afirmar que se trata de “una exposición compleja. Responde al interés de la artista por reafirmar una reflexión sobre el mundo del arte y el de la persona en la sociedad finisecular. Mediante una disposición unitaria y bajo un título común plantea una dispersa referencialidad hecha de cuestiones diferentes que se entrelazan creando familias de asociaciones. La tensión resultante es un hecho" ${ }^{\prime 4}$.

Otro apartado de interés abordado en el texto del catálogo hace referencia al tema del poder, extrayendo dos reflexiones:

1-El artista parece necesitar el derecho a su propio poder, como elemento para diferenciarse de otros, de esta manera le sirve como elemento de apoyo para su propia autosuficiencia y sus propios intereses personales.

La defensa del individualismo es el verdadero soporte de la defensa del poder. Amelia Varcárcel afirma que "aún hoy es de recibo en la retórica ético-política denostar el individualismo disgregador y corruptor y es un serio tema para la filosofía moral, o así al menos lo desarrollan algunos, separar el individualismo solidario del llamado individualismo posesivo, que viene a ser el individualismo a secas" ${ }^{\prime 4}$. Este proceso de continua individualización es criticado por esta escultora, ya que mientras el individuo continúe manteniendo su postura y actitud de diferenciación y superación respecto al resto de los individuos, este seguirá necesitando del poder.

Sobre el tema del individualismo, Juan Antonio Álvarez Reyes realiza una interesante reflexión ${ }^{45}$, afirmando que para la generación de jóvenes artistas de los años 80, su juventud comienza con la desaparición del régimen anterior, no interviniendo en los diversos cambios sociales y políticos que se materializaron. No obstante, deben vivir en un contexto socio-económico caracterizado por altas tasas de paro, el cuestionamiento de las diversas ideologías

${ }^{43}$ X. SÁENZ DE GORBEA, "Burlas Expresionistas", en AA.VV. María Luisa Fernández. Burlas Expresionistas, ... s/n.

${ }^{44}$ A. VARCÁRCEL, Ética contra estética, Barcelona, 1998, pp. 140-141.

${ }^{45}$ J.A. ÁLVAREZ REYES, "Problemática del arte joven español de la década de los ochenta", en P. RODRÍGUEZ-ESCUDERO, Op. cit., p. 178. 
(socialismo real y marxismo entre ellos) y el proyecto ilustrado, asumiendo que la generación del 68, instalada en el poder, había sido incapaz de introducir los cambios prometidos. De ahí, su desencanto ante las acciones colectivas y una retirada hacia el individualismo. Igualmente, para Valeriano Bozal, el sujeto se transforma en el único protagonista, pero desde una posición egoísta, ya que se desentiende del colectivo social. Es el triunfo del individualismo, de la insolidaridad ${ }^{46}$. Esta situación conlleva la desideologización de una buena parte de los jóvenes artistas, asumiendo esta realidad con gran naturalidad. Igualmente, "el artista preso de escepticismo por la evolución del mundo, se desentiende del acontecer social y político, refugiándose en su propia individualidad. Si los esfuerzos realizados por transformar la sociedad son infructuosos como parece cada día más evidente, el artista debe retornar a su verdadero objetivo: la expresión personal, de la que un día lejano fue reclamado para colaborar activamente en la reforma o en la revolución de la sociedad. Este vendría a ser el razonamiento de los artistas que de algún modo se declaran impotentes para seguir luchando ante una situación tan poco propicia" $^{47}$.

2-Esta auto-suficiencia requiere de un apoyo económico, de una clientela $\mathrm{y}$, en definitiva, de unos mecenas, que evidentemente provienen de una clase acomodada y empresarial que apoya, en definitiva, la diferenciación de clases y la superioridad de su clase. En este sentido, es evidente que el artista que se encuentra en esta situación no sólo se adecua al marco, las normas y las reglas marcadas por esta clase, que defiende el Poder, sino que a modo de sustento procura que no se ataque esta realidad. Rechaza posturas más conflictivas y beligerantes, desarrollando un arte amable y benevolente con el Poder. Para esta crea-

${ }^{46} \mathrm{~V}$. BOZAL, "Fin de siglo. Notas para una teoría de la época", La Balsa de la Medusa, no 1, 1987, pp. 13-28.

${ }^{47}$ J. HERNANDO CARRASCO, Op. cit., p. 264. dora, esta opción es la más apoyada: rehusar la libertad y, por contrapartida, obtener un apoyo real en las necesidades económicas. En relación con esta opinión, veamos el siguiente comentario de Valeriano Bozal al afirmar que el discurso sobre las nuevas tecnologías "sustituye cualquier proyecto revolucionario por el bien conservador de la modernización, acompañándolo con un realismo sobre los objetivos a medio y corto plazo: no transformar la estructura de las relaciones sociales y mucho menos la del poder"48. Esto conlleva una legitimización del poder sobre la base del propio desarro1lo tecnológico, desapareciendo términos como moral y justicia. Este es el discurso que prende en la sociedad occidental postindustrial de los años 80, favorecido por la crisis del socialismo real y del pensamiento marxista.

En una línea similar, Lucy R. Lipard afirma que el poder generalmente se interpreta como control, tanto sobre las propias acciones como sobre las ajenas. Si el primer ingrediente del poder del arte es su capacidad para comunicar lo visto, el segundo es el control sobre los contextos sociales e intelectuales en los que se distribuye e interpreta $^{49}$. Igualmente, para Jean Baudrillard, la única arma del poder consiste en reinyectar realidad y referencialidad en todas partes, a fin de convencernos de la realidad de lo social, de la gravedad de la economía y de los fines de la producción. Para este propósito, se utiliza el discurso de la crisis y el discurso del deseo, ya que en un mundo no referencial incluso la confusión del principio de realidad con el principio de deseo es menos peligrosa que la contagiosa hiperrealidad ${ }^{50}$.

${ }^{48}$ V. BOZAL, Op. cit., pp. 13-28.

${ }^{49}$ L. R. LIPPARD, “Caballos de Troya: arte activista y poder", en B. WALLIS (ed.), Arte después de la modernidad. Nuevos planteamientos en torno a la representación, Madrid, 2001, p. 349.

${ }^{50}$ Para obtener más información sobre este tema, remitirse a J. BAUDRILLARD, "La precesión de los simulacros", en B. WALLIS, Op. cit., pp. 253-281. 